\title{
Induction of apoptosis by casticin in cervical cancer cells through reactive oxygen species-mediated mitochondrial signaling pathways
}

\author{
DAN CHEN, JIANGUO CAO, LI TIAN, FEI LIU and XIFENG SHENG \\ Medical College, Hunan Normal University, Changsha 410013, P.R. China
}

Received May 13, 2011; Accepted June 20, 2011

DOI: 10.3892/or.2011.1367

\begin{abstract}
Casticin, one of the main components from Fructus Viticis, has been reported to inhibit the growth of various cancer cells, including the human cervical cancer cell line HeLa. The purpose of this study was to examine the apoptotic activity and molecular mechanism of casticin action on human cervical cancer cells. The apoptotic activity of casticin on human cervical cancer $\mathrm{HeLa}$, CasKi, SiHa and peripheral blood mononuclear cells (PBMCs) was measured using a histone/DNA ELISA assay, flow cytometry with propidium iodide (PI) staining and DNA agarose gel electrophoresis. The mitochondrial membrane potential and reactive oxygen species (ROS) production were evaluated by flow cytometry analysis. Caspase activities were assayed using a caspase colorimetric activity assay kit. Protein expression levels of cytochrome c, Bax, Bcl-2, Bcl-xL and XIAP were analyzed by Western blotting. Casticin caused accumulation of the Sub-G1 cells and increased reactive oxygen species (ROS) production in HeLa, CasKi, SiHa cell lines, but not in PBMCs. Apoptosis of HeLa cells was induced by casticin via mitochondrial release of cytochrome $\mathrm{c}$ due to the reduction of mitochondrial transmembrane potential, activation of caspase-3 and -9 , and the production of reactive oxygen species. The pan caspase inhibitor zVAD-FMK, the caspase-9 inhibitor zLEHDfmk and $N$-acetylcysteine suppressed casticin-induced apoptosis. Bax was upregulated, while expression levels of Bcl-xL and XIAP were downregulated. However, there was no change in the expression of $\mathrm{Bcl}-2$ under the same treatment. Our results indicate that casticin-induced apoptosis of cervical cancer cells is mediated by ROS generation and mitochondrial signaling pathways.
\end{abstract}

\section{Introduction}

Cervical cancer is one of the most common malignancies in the world among women $(1,2)$. About 500,000 new cervical

Correspondence to: Dr Jianguo Cao, Medical College, Hunan Normal University, Changsha 410013, P.R. China

E-mail: caojianguo2005@yahoo.com.cn

Key words: human cervical cancer, casticin, apoptosis, reactive oxygen species, mitochondria cancer cases are diagnosed every year, with a five-year survival rate of about only $52 \%(3,4)$. Currently, we generally utilize radiotherapy and/or chemotherapy as a strategy in the clinical treatment of cervical cancer, thereby inducing apoptosis in tumor cells (5-8). However, conventional therapeutic drugs not only trigger apoptosis but also exert lethality on normal cells, resulting in serious toxicity (5-8). Therefore, clinically speaking, it is important for us to develop effective, new treatments for human cervical cancer that can induce apoptosis with higher selectivity and lower toxicity.

Casticin is one of the main components from Fructus Viticis (Manjingzi is the Chinese name), which is a traditional Chinese medicine prepared from the fruit of Vitex trifolia L. (family Verbenaceae) that is also used as a folk medicine, is known to be an anti-inflammatory agent, and is used to treat certain cancers in China (9). The chemical structure of casticin is shown in Fig. 1. It has been shown that the C-3' and C-5 hydroxyl as well as the C-3 and C-4' methoxyl groups are required for the significant antiproliferative activity of flavone and that casticin (5,3'-dihydroxy-3,6,7,4'-tetramethoxylflavone, also called vitexicarpin) also contains these groups (10). Casticin has been reported to inhibit the proliferation and growth of a variety of cancer cells, including human cervical cancer cells (HeLa) (10-14). Therefore, it is worth investigating whether casticin can induce apoptosis in HeLa cells and the molecular mechanisms by which casticin causes apoptosis.

Work from our laboratory and others previously demonstrated that similar flavones, such as apigenin (15), chrysin (16), luteolin (17) and quercetin (18), cause a higher level of reactive oxygen species (ROS) in cancer cells than in normal cells, resulting in cytotoxicity. In the present study, we examined the effects of casticin on the apoptosis of human cervical cancer cell lines. We show for the first time that casticin causes mitochondrial membrane potential collapse, cytochrome $\mathrm{c}$ release, caspase- 3 and -9 activation and apoptotic cell death triggered by ROS generation in human cervical cancer cells.

\section{Materials and methods}

Drugs and chemical reagents. Casticin was purchased from Chengdu Biopurify Phytochemicals Ltd. (Chengdu, China). Casticin has a molecular weight of $374.3 \mathrm{ku}$, appears as yellow crystals and has a purity of $98.0 \%$. Casticin was prepared in 
dimethyl-sulfoxide (DMSO) at a concentration of $10 \mathrm{mmol} / \mathrm{l}$, and aliquots were stored at $-80^{\circ} \mathrm{C}$. Stock solutions were diluted to the desired final concentrations with growth medium just prior to use. The following were purchased from Hunan Clonetimes Biotech Co., Ltd. (Changsha, China): Dulbecco's modified Eagle's medium (DMEM; Invitrogen), RPMI-1640 medium (Invitrogen), fetal bovine serum (Invitrogen), Cell Apoptosis ELISA detection kit (Roche), Caspase-3 Activity detection kit (Millipore, Bedford, MA), Caspase-9 colorimetric Activity assay kit (Millipore), propidium iodide (PI; Sigma), ethidium bromide (EB; Sigma), Apoptotic DNA Ladder detection kit (Bodataike Company, Beijing), 2',7'-dichlorofluorescein diacetate (DCFH-DA; Molecular Probes Inc, Eugene, OR), CBZ-Val-Ala-Asp-fluoromethyl ketone (zVAD-fmk: Livermore), CBZ-Leu-Glu(OMe)-HisAsp(OMe)-fluoromethyl ketone (zLEHD-fmk: Livermore), mouse anti-human Bcl-2, Bax, XIAP, Bcl-XL, cytochrome c and $\beta$-actin antibodies (Santa Cruz Biotechnology), and horseradish peroxidase-conjugated anti-mouse secondary antibody (Cell Signaling Technology).

Cell lines and cell culture. Human cervical cancer cell lines ( $\mathrm{HeLa}, \mathrm{CasKi}$ and $\mathrm{SiHa}$ ) were purchased from the China Centre for Type Culture Collection (CCTCC; Wuhan, China), were maintained in DMEM supplemented with $10 \%$ fetal bovine serum, $4 \mathrm{mM}$ glutamine, $100 \mathrm{U} / \mathrm{ml}$ penicillin and $100 \mu \mathrm{g} / \mathrm{ml}$ streptomycin, and were incubated at $37^{\circ} \mathrm{C}$ in a humidified atmosphere of $5 \% \mathrm{CO}_{2}$. Normal human peripheral blood mononuclear cells (PBMCs) were isolated by Ficoll-Paque (Amersham Biosciences, Uppsala, Sweden) density-gradient centrifugation and were cultured in RPMI1640 medium supplemented with $20 \%$ FBS. PBMCs were acquired from a healthy volunteer after obtaining informed consent.

Histone/DNA ELISA for detecting apoptosis. The cell apoptosis ELISA detection kit (Roche) was used to detect apoptosis in cells treated with casticin according to the manufacturer's protocol. Briefly, cells were seeded in a 96-well plate at a density of $1 \times 10^{4}$ cells/well for $24 \mathrm{~h}$, and testing agents were then added to culture medium containing $10 \%$ fetal bovine serum. After $24 \mathrm{~h}$, we transferred the cytoplasm of the control and treatment groups to the 96-well plate pre-coated with streptavidin and previously incubated with the biotinylated histone antibody and the peroxidase-tagged mouse anti-human DNA for $2 \mathrm{~h}$ at room temperature. Absorbance was measured at $405 \mathrm{~nm}$ using the EXL-800-type enzyme-linked immunosorbent apparatus (Bio-Tek, Shanghai).

Flow cytometry Analysis using PI staining. Cells were seeded at a density of $4 \times 10^{6}$ cells/well in $100 \mathrm{ml}$ culture flasks for $24 \mathrm{~h}$ followed by treatment with medium containing various concentrations of casticin with $10 \%$ fetal bovine serum for $24 \mathrm{~h}$ or $4.0 \mu \mathrm{M}$ casticin for the indicated time. Propidium iodide staining to analyze DNA content was performed as previously described (16).

DNA agarose gel electrophoresis. Cells were seeded at a density of $4 \times 10^{6}$ cells/well in $250 \mathrm{ml}$ culture flasks for $24 \mathrm{~h}$ and treated with medium containing various concentrations of the

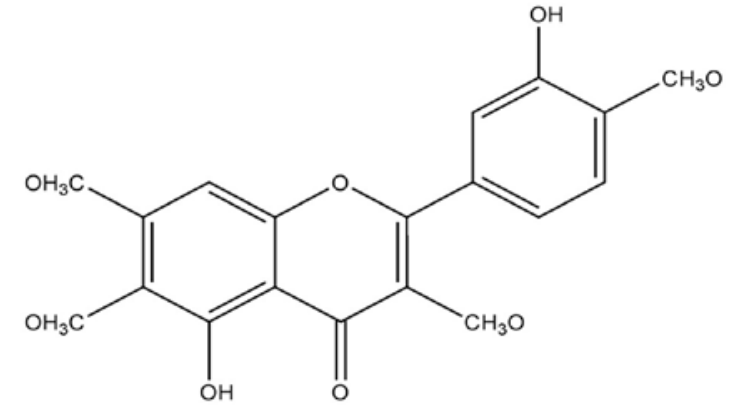

Figure 1. The chemical constitution of casticin.

test/control agents or vehicle with $10 \%$ fetal bovine serum for $24 \mathrm{~h}$. This assay was performed as previously described (16).

Determination of reactive oxygen species. Intracellular ROS accumulation was measured by FCM using the fluorescent probe DCHF-DA as prevîously described (16). Cells $\left(2 \times 10^{6}\right)$ were collected after treatment with various concentrations of test agents and washed with serum-free medium and incubated with $1 \mathrm{ml} \mathrm{DCHF}-D A$ for $30 \mathrm{~min}$ at $37^{\circ} \mathrm{C}$ in the dark. After incubation, the cells were washed with serum-free medium three times and analyzed within 30 min by FCM (American BD Company, FACS420) at an excitation wavelength of $488 \mathrm{~nm}$ and an emission wavelength of $525 \mathrm{~nm}$.

Measurement of mitochondrial transmembrane potential. Mitochondrial membrane potential was measured by flow cytometry using the cationic lipophilic green fluorochrome rhodamine-123 (Rh123) (Molecular Probes). Disruption of $\Delta \Psi \mathrm{m}$ is associated with a lack of Rh123 retention and a decrease in fluorescence. Briefly, the cells were washed twice with PBS and incubated with $1 \mu \mathrm{g} / \mathrm{ml} \mathrm{Rh} 123$ at $37^{\circ} \mathrm{C}$ for $30 \mathrm{~min}$. Then, the cells were washed twice with PBS, and Rh123 intensity was determined by flow cytometry. Cells with reduced fluorescence (less Rh123) were counted as having lost some of their mitochondrial membrane potential.

Analysis of caspase-3 and -9 activities. Analysis of caspase-3, and -9 activities was performed using the Caspase apoptosis detection kit according to the manufacturer's instructions. In brief, cell lysates were prepared after the respective treatment with tested agents. Assays were performed in 96-well plates by incubating $20 \mu \mathrm{g}$ cell lysates in $100 \mu \mathrm{l}$ reaction buffer ( $1 \%$ NP-40, 20 mM Tris- $\mathrm{HCl}$ (pH 7.5), $137 \mathrm{mM} \mathrm{NaCl}, 10 \%$ glycerol) containing $5 \mu \mathrm{M}$ of the caspase-3 substrate, Ac-DEVD- $p$ NA, or the caspase-9 substrate, Ac-LEHD- $p$ NA. Lysates were then incubated at $37^{\circ} \mathrm{C}$ for $2 \mathrm{~h}$. Next, absorbance was measured at $405 \mathrm{~nm}$ with an enzyme-labeling instrument (ELX-800 type, Bio-Tek). In the caspase inhibitors assay, cells were pretreated with a caspase inhibitor $(20 \mu \mathrm{M}$ of zVAD-fmk, zDEVD-fmk, zIETD-fmk or zLEHD-fmk) for $1 \mathrm{~h}$ prior to the addition of test agents.

Cellular fractionation. To assay the release of cytochrome $\mathrm{c}$, cells were fractionated into cytosolic and mitochondrial fractions as described by Ling et al (19). Briefly, cells were incubated in a buffer containing $20 \mathrm{mM}$ HEPES-KOH, 
A

\section{.}

C

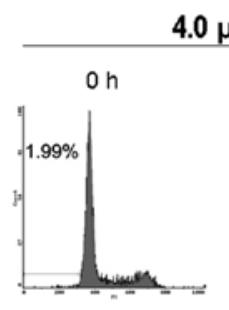

4.0 $\mu \mathrm{M}$ Casticin treatment
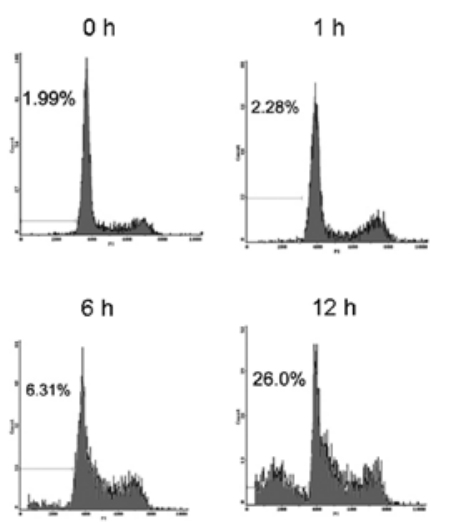

B

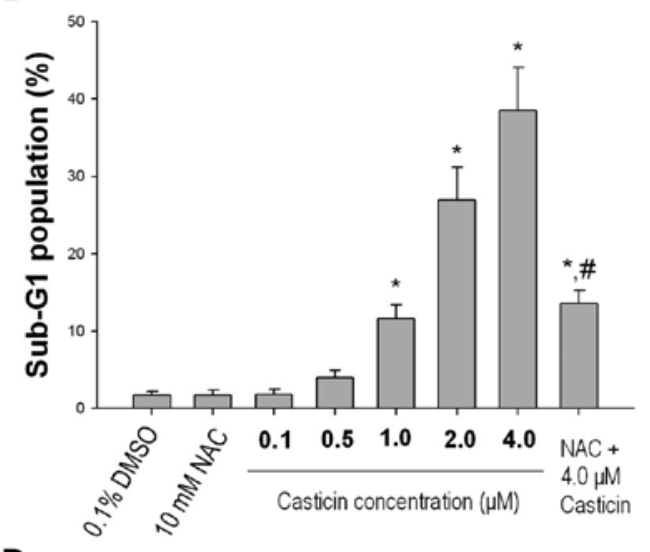

D

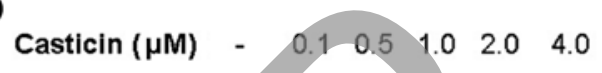

Figure 2. Casticin induces DNA fragmentation (A), sub-G1 population accumulation (B and C) and a DNA ladder (D) in HeLa cells. HeLa cells were treated with casticin at the indicated concentration for $24 \mathrm{~h}$ or $4.0 \mu \mathrm{M}$ for the indicated time. The data are shown as the mean $\pm \mathrm{SD}$, $\mathrm{n}=3$, ${ }^{*} \mathrm{P}<0.05 \mathrm{vs}$. treatment with DMSO; ${ }^{\text {P }}<0.05$ vs. treatment with $10 \mu \mathrm{M}$ casticin alone.

pH 7.2, $10 \mathrm{mM} \mathrm{KCl,} 1.5 \mathrm{mM} \mathrm{MgCl}_{2}, 1 \mathrm{mM}$ EDTA, $0.1 \mathrm{mM}$ phenylmethylsulfonyl fluoride, $10 \mu \mathrm{g} / \mathrm{ml}$ leupeptin, and $10 \mu \mathrm{g} / \mathrm{ml}$ aprotinin at $4^{\circ} \mathrm{C}$ for $10 \mathrm{~min}$ and homogenized with a Dounce homogenizer for 20 strokes. After the addition of buffer containing $210 \mathrm{mM}$ mannitol, $70 \mathrm{mM}$ sucrose, $5 \mathrm{mM}$ EGTA, and $5 \mathrm{mM}$ Tris-HCl, $\mathrm{pH} 7.5$, the homogenates were centrifuged at $1,000 \times \mathrm{g}$ for $10 \mathrm{~min}$ at $4^{\circ} \mathrm{C}$. Supernatants were further centrifuged at $15,000 \mathrm{xg}$ for $30 \mathrm{~min}$ at $4^{\circ} \mathrm{C}$ and the cytosolic fraction was collected.

Western blot analysis. Total cell extracts were obtained as previously described (16). Cell lysates containing $50 \mu \mathrm{g}$ of protein were separated on a $7.5 \%$ to $15 \%$ SDS-polyacrylamide gel for electrophoresis and then blotted onto polyvinylidene difluoride (PVDF) membranes (Millipore). Anti-Bcl-2, anti-Bax, anti-XIAP, anti-Bcl-XL, anti-cytochrome $\mathrm{c}$ and anti- $\beta$-actin (1:1000 dilutions for each) were used as primary antibodies. Signals were detected using an ECL kit (Amersham Pharmacia Biotech, Piscataway, NJ). Images were scanned and densitometry analysis was performed using Alphazmager 2200 software (Silk Scientific).The ratios of the signal from specific antibodies to $\beta$-actin signals were determined to measure the expression levels of each protein.

Statistical analysis. A database was set up using the SPSS 15.0 software package (SPSS Inc, Chicago, IL) for statistical analysis. Data are presented as the mean \pm SD. The means of multiple groups were compared with one-way ANOVA, after the equal check of variance, and the two-two comparisons among the means were performed using the LSD method. Statistical comparison was also performed using the twotailed t-test when appropriate. $\mathrm{P}<0.05$ was considered to be statistically significant.

\section{Results}

Effects of casticin on apoptosis in HeLa cells. Casticin significantly inhibits the proliferation of HeLa cells with an $\mathrm{IC}_{50}$ of $1.286 \mu \mathrm{M}$ (10). To elucidate whether casticin inhibits cell proliferation through the induction of apoptosis in HeLa cells, we first examined the effects of casticin on apoptosis in HeLa cells using various approaches. After $24 \mathrm{~h}$ of exposure, casticin significantly induced histone/DNA fragmentation in a concentration-dependent manner (Fig. 2A). Fig. 2B and C show that casticin treatment resulted in a dose- and timedependent increase of the Sub-G1 population in HeLa cells $(\mathrm{P}<0.05)$. After treatment with casticin at concentrations of 2.0 and $4.0 \mu \mathrm{M}$, respectively, $26.9 \pm 4.3 \%$ and $38.5 \pm 5.6 \%$ of HeLa cells underwent apoptosis with typical DNA ladder (Fig. 2B and D). Taken together, these results demonstrate that casticin effectively induces the apoptotic cell death of HeLa cells. 
A

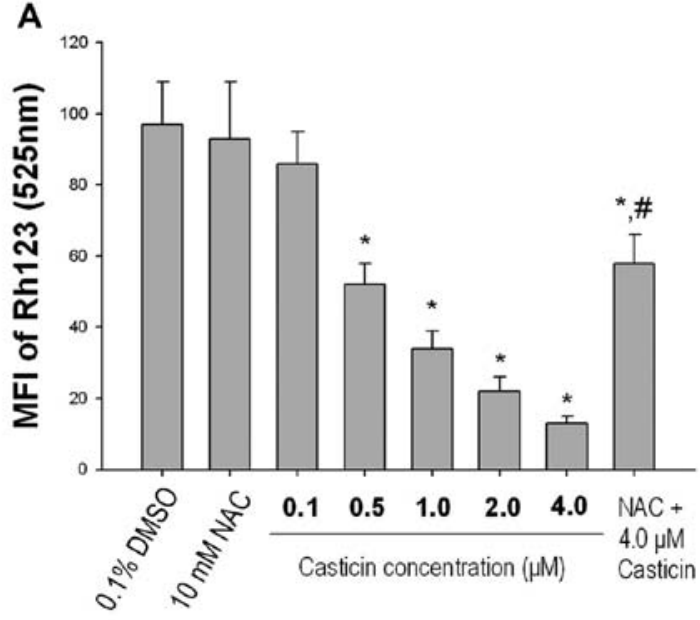

C

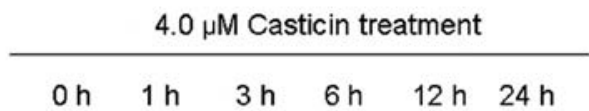

Cyto C

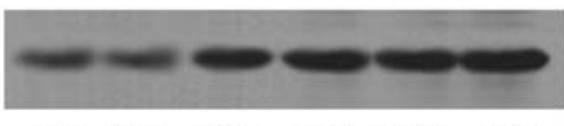

$1.00 \quad 0.95 \quad 3.85^{\star} \quad 5.36^{*} \quad 5.21^{*} \quad 6.35^{\star}$
B

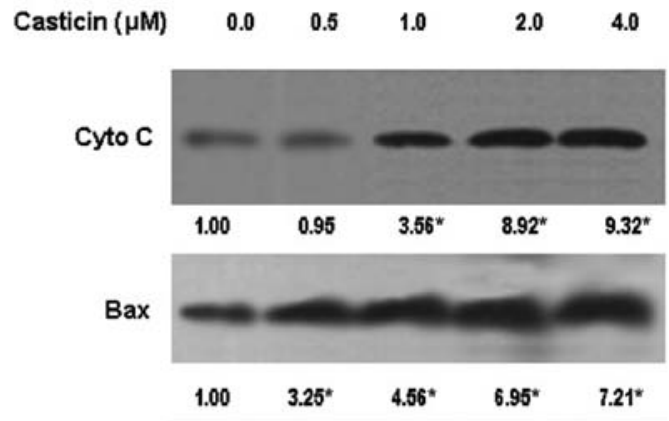

$\mathrm{Bcl}-2$

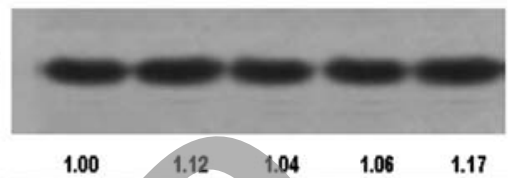

$\mathrm{Bcl-XL}$

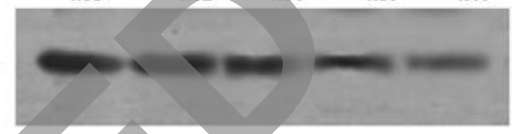

Actin

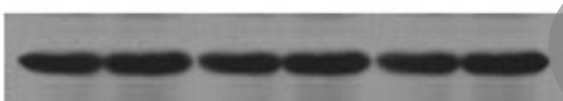

Figure 3. Effects of casticin on mitochondrial membrane potential (A), cytochrome c release (B and C) and Bax/Bcl-2/Bcl-XL/XIAP protein expression (B) in HeLa cells. HeLa cells were treated with casticin at the indicated concentrations for $24 \mathrm{~h}$ or $4.0 \mu \mathrm{M}$ for the indicated time. The data are shown as the mean $\pm \mathrm{SD}$, $\mathrm{n}=3,{ }^{*} \mathrm{P}<0.05$ vs. treatment with DMSO or $0 \mathrm{~h} ;{ }^{*} \mathrm{P}<0.05$ vs, treatment with $10 \mu \mathrm{M}$ casticin alone.
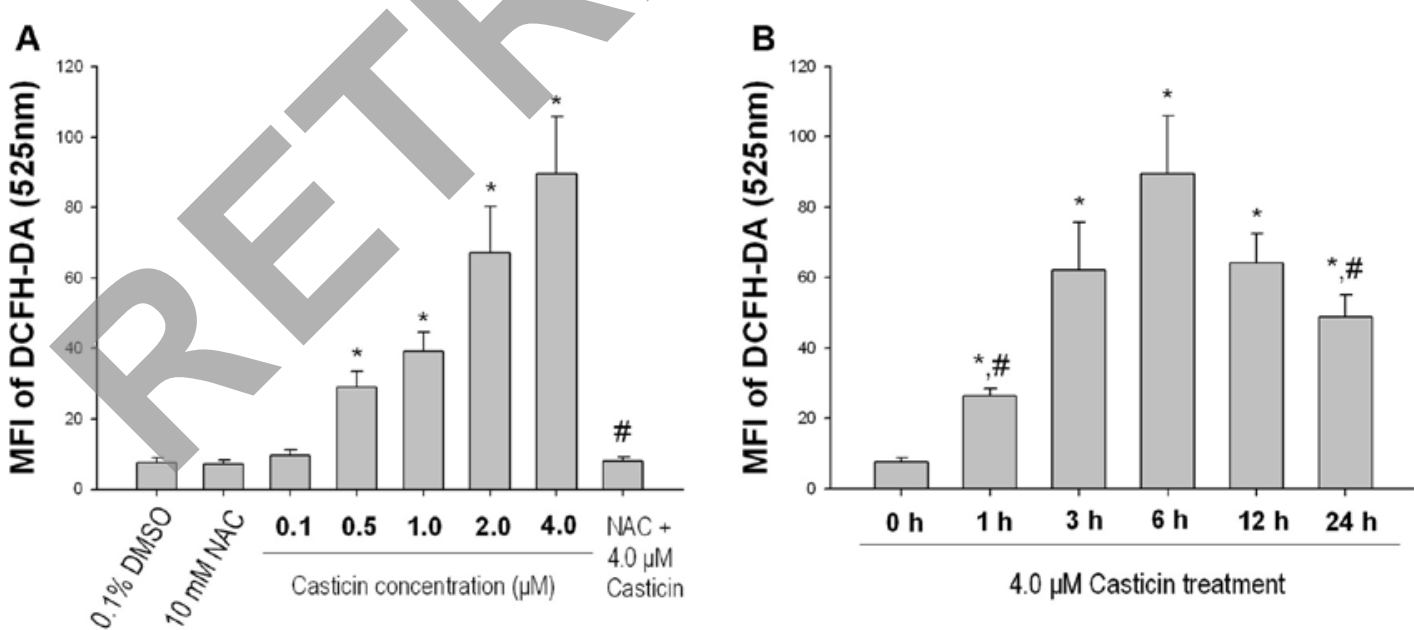

Figure 4. Casticin induces the generation of reactive oxygen species in a concentration-dependent manner (A) and time-dependent manner (B) in HeLa cells. HeLa cells were treated with casticin at the indicated concentration for $6 \mathrm{~h}$ or $4.0 \mu \mathrm{M}$ for the indicated time. The data are shown as the mean $\pm \mathrm{SD}, \mathrm{n}=3$, ${ }^{*} \mathrm{P}<0.05$ vs. treatment with DMSO or $0 \mathrm{~h} ;{ }^{*} \mathrm{P}<0.05$ vs. treatment with $4.0 \mu \mathrm{M}$ casticin alone or $6 \mathrm{~h}$.

Effects of casticin on mitochondrial signaling pathways for apoptosis of HeLa cells. Disruption of mitochondrial integrity is one of the early events leading to apoptosis. Therefore, we next examined the effects of casticin on several important events in the mitochondrial apoptotic pathway. The results in Fig. 3 indicate the following: i) the treatment with casticin clearly elicited mitochondrial transmembrane potential $(\Delta \Psi \mathrm{m})$ dissipation, as indicated by the decrease in rhodamine 123-derived fluorescence in flow cytometry assays (Fig. 3A) and ii) casticin triggered a rapid release of cytochrome $\mathrm{c}$ from the mitochondria to the cytoplasm, as determined by immunoblot staining using cytosolic extracts. The release of cytochrome c occurred as early as $3 \mathrm{~h}$ after treatment and, therefore, preceded the increase of sub-G1 populations, which occurred after a 12-h treatment in HeLa cells (Figs. 2C and $3 \mathrm{C})$, and iii) the treatment with casticin did not affect total 
A

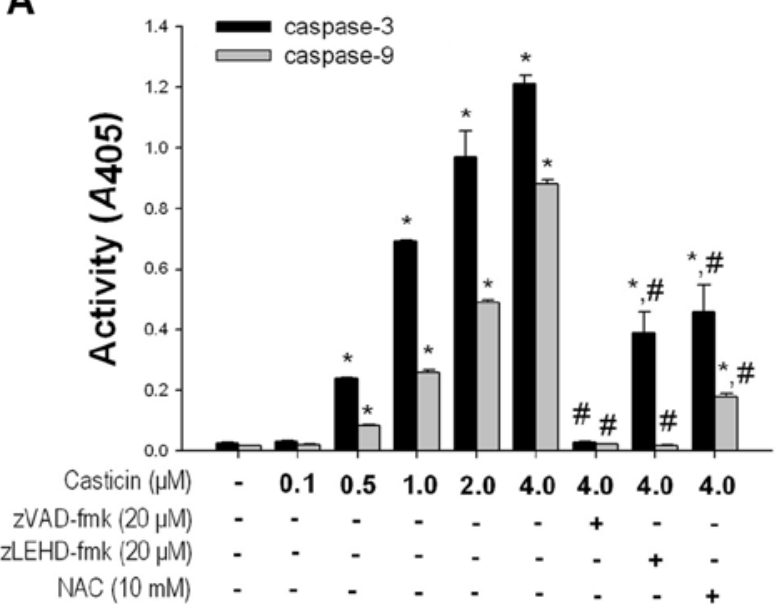

B

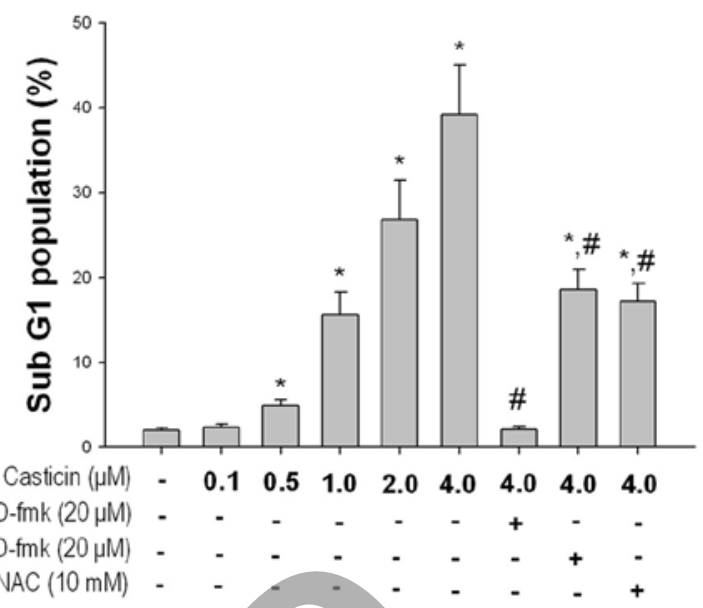

Figure 5. Casticin activates caspase-3 and -9 (A) and induces sub-G1 population accumulation (B) in HeLa cells. HeLa cells were treated with casticin at the indicated concentration for $24 \mathrm{~h}$. The data are shown as the mean $\pm \mathrm{SD}, \mathrm{n}=3,{ }^{*} \mathrm{P}<0.05$ vs. treatment with DMSO or 0 h; " $\mathrm{P}<0.05$ vs. treatment with $4.0 \mu \mathrm{M}$ casticin alone or $6 \mathrm{~h}$.

Bcl-2 expression but caused decreases in Bcl-XL and XIAP expression levels and an increase in Bax expression (Fig. 3B). These data demonstrate that casticin-induced apoptosis is involved in the mitochondrial death pathway.

Effects of casticin on ROS generation in HeLa cells. Changes in MTP are considered to involve ROS production (20). Thus, we examined whether casticin promoted ROS generation in HeLa cells. As expected, after the treatment of HeLa cells with $0.5,1.0,2.0,4.0 \mu \mathrm{M}$ casticin for $6 \mathrm{~h}$, the level of ROS increased in a dose-dependent manner and was abrogated by pre-treatment with $10 \mathrm{mM}$ of the thiol-containing antioxidant NAC (Fig. 4A). Time course experiments revealed that the levels of ROS increased initially at $1 \mathrm{~h}$, reached a peak at $6 \mathrm{~h}$ and persisted for up to $24 \mathrm{~h}$ after treatment with $4.0 \mu \mathrm{M}$ casticin (Fig. 4B).

To determine a link between the elevation of intracellular ROS levels and apoptotic cell death in casticin-treated cells, HeLa cells were pre-incubated with the antioxidant NAC before treatment with casticin. The Sub-G1 population and histone/ DNA fragmentation were both reduced with the combination of casticin and NAC (Fig. 2A and B). These findings provide the evidence that apoptosis induced by casticin in HeLa cells is dependent upon the generation of ROS.

Effects of casticin on caspase activities in HeLa cells. To determine the effectors active in casticin-induced apoptotic pathways, we next examined whether caspase- 3 and -9 were actually activated during casticin-induced cell death of HeLa cells. Fig. 5A shows that treatment of HeLa cells with casticin for $24 \mathrm{~h}$ increased the levels of active caspase- 3 and $-9(\mathrm{P}<0.05)$ in a concentration-dependent manner.

We further examined the role of caspase activation during casticin-induced apoptosis by flow cytometry using the pancaspase inhibitor zVAD-fmk and the caspase-9 inhibitor zLEHD-fmk. Fig. 5B shows that zVAD-fmk completely abrogated and zLEHD-fmk attenuated casticin-induced accumulation of Sub-G1 population. These data indicate that casticin-induced apoptosis is essentially dependent on the activation of caspase-3 and -9 in HeLa cells.
Effects of casticin on apoptosis and ROS generation in other human cervical cancer cell lines and in normal human PBMCs. We next investigated whether casticin induces apoptosis and ROS generation in other cervical cancer cells using human cervical cancer cell lines, including CasKi and SiHa. Casticin induce the accumulation of sub-G1 population in a dosedependent manner in both cell lines (Fig. 6A). Similar results were obtained when ROS generation was monitored by FCM using a DCFH-DA probe (Fig. 6B). Together, these findings suggest that the induction of apoptosis and ROS generation by casticin is not specific to HeLa cell line.

Since we found that casticin induced apoptosis and ROS generation in HeLa, CasKi and SiHa cells, we next examined the effect of casticin treatment on normal human cells. The side effects of chemotherapeutic agents on hematopoietic cells are a major problem during clinical treatment. Therefore, we used normal human PBMCs as a model cell line. The level of intracellular ROS was not significantly different in normal human PBMCs after treatment with casticin (Fig. 6C). Furthermore, casticin did not induce the accumulation of sub-G1 population in normal human PBMCs (Fig. 6D).

\section{Discussion}

Casticin, a polymethoxyflavone from Fructus Viticis that is widely used as an anti-inflammatory agent in Chinese traditional medicine (9), was reported to inhibit the proliferation of a various cancer cell lines (10-14). Csupor-Loffler et al demonstrated that casticin significantly inhibited the proliferation of human cervical cancer HeLa cell lines (10). Our present study demonstrated for the first time that casticin: i) dose-dependently induced apoptosis in human cervical cancer cell lines (HeLa, CasKi and SiHa), ii) led to a concentration-dependent generation of ROS, iii) induced apoptosis of HeLa cells through the generation of ROS, iv) triggered the activation of mitochondrial signaling in a ROS-dependent manner in HeLa cells and v) did not induce apoptosis or ROS production in PBMCs. Therefore, our results warrant additional studies on the therapeutic activity of casticin in vivo. It should be pointed 
A

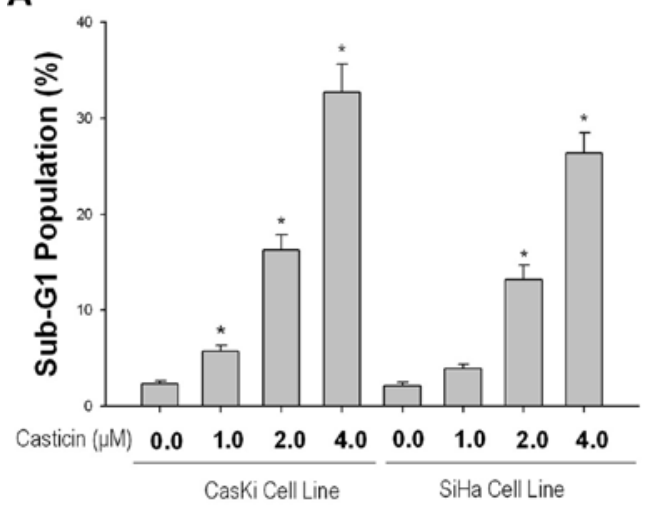

C

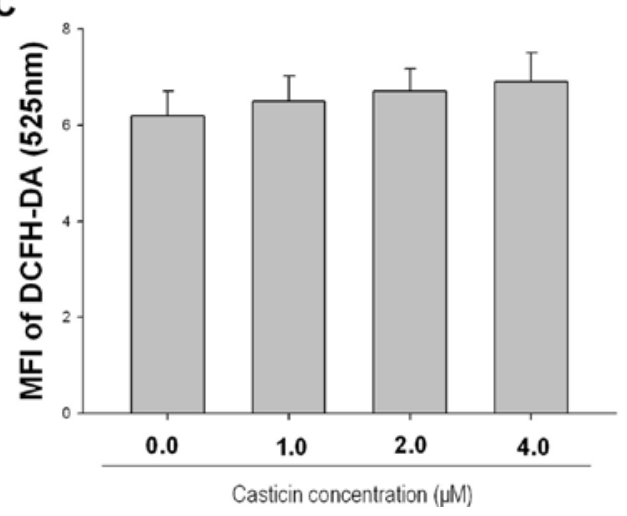

B

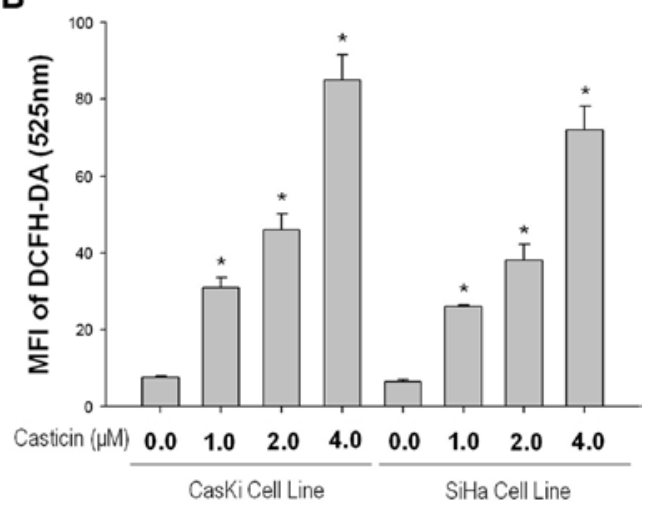

D

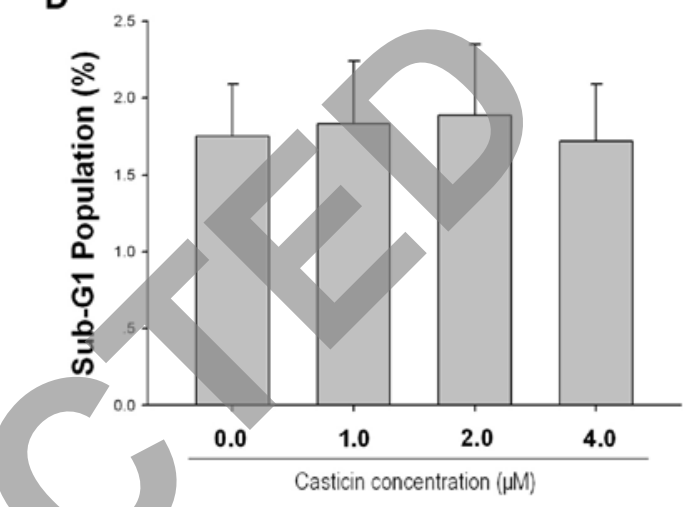

Figure 6. Effects of casticin on the generation of reactive oxygen species and sub-G1 population accumulation in CasKi and SiHa cell lines (A and B) and human peripheral blood mononuclear cells (PBMCs; $\mathrm{C}$ and D). Cells were treated with casticin at the indicated concentration for $24 \mathrm{~h}$ (to detect the sub-G1 population) or $6 \mathrm{~h}$ (to detect reactive oxygen species). ${ }^{*} \mathrm{P}<0.05$ vs. treatment with $\mathrm{DMSO}$.

out that casticin inhibited cell growth or induced apoptotic cell death not only in cervical cancer cells but also in other types of cancer cells, including human prostate, colon, oral epidermoid carcinoma, breast cancer, and leukemia cells (10-14,21-23).

The cancer suppressor p53 is an important factor that affects a cell's response to drugs, specifically the effects on growth inhibition and apoptosis induction (24). The majority of evidence supports the notion that cells with wild-type p53 exhibit increased sensitivity to radiation or chemotherapeutic agents, whereas cells lacking wild-type p53 expression still undergo apoptosis but need a relatively high dose of radiation or chemotherapeutic drugs (24). Haïdara et al demonstrated that casticin induced apoptotic cell death in p53 mutant or null breast cancer cell lines (21). In the present study, we found that casticin induced apoptosis in p53 mutated human cervical cancer HeLa cells (10). Therefore, we conclude that casticin-induced apoptosis in human cervical cancer cells is p53-independent.

Apoptosis can be initiated via two alternative signaling pathways: the death receptor-mediated extrinsic apoptotic pathway and the mitochondrial-mediated intrinsic apoptotic pathway $(25,26)$. Mitochondria play critical roles in the regulation of various apoptotic processes, including drug-induced apoptosis (27). The mitochondrial death pathway is controlled by members of the Bcl-2 family, which play a central regulatory role to decide the fate of the cells via the interaction between pro- and anti-apoptotic members $(28,29)$. Bax, a proapoptotic protein in the Bcl-2 family, was upregulated, thereby indicating the involvement of the mitochondria because
Bax forms channels at the outer mitochondrial membrane to facilitate the release of cytochrome c $(30,31)$. Activation of mitochondrial permeability transition is required for the complete release of cytochrome c $(32,33)$. Our results show that casticin did not alter the expression levels of Bcl-2 but instead downregulated Bcl-XL and upregulated Bax expression levels. Whether the increase in the ratio of $\mathrm{Bax} / \mathrm{Bcl}-\mathrm{XL}$ plays a role in casticin-induced apoptosis of cervical cancer cells remains to be elucidated. It has been reported that the release of cytochrome $\mathrm{c}$ from the mitochondria to the cytosol is required for apoptosome assembly and subsequent activation of caspase9/-3, along with the downregulation of XIAP, which relieves caspases from its inhibitory action (34). Moreover, IAPs are degraded by the ubiquitin-proteasome system (35), and earlier studies reported an increase in ubiquitin-conjugated proteins in flavonoid-treated cells (36). Therefore, the downregulation of XIAP likely reflects an increase in protein degradation. Our findings demonstrate that casticin-induced apoptosis of human cervical cancer cells utilizes the mitochondrial death pathway.

ROS, active, transitory and oxygenic compounds, including $\mathrm{H}_{2} \mathrm{O}_{2}, \mathrm{O}_{2}$, and hydroxyl radicals, are metabolites of biochemical processes in the body. There is an integrated system to clear ROS in the body to keep balance. Oxidation of cell membrane phospholipids, enzymes and DNA $(37,38)$ by high levels of ROS can alter the function of signal transduction pathways, platelet aggregation, immune control, and the regulation of cell growth, and can also cause necrosis or apoptosis $(39,40)$. Since the generation of ROS is the result of disordered mitochondria function and metabolite augmentation, there 
may be ways to regulate ROS selectively in cancer cells (41). We made use of FCM using a DCFH-DA probe to measure ROS after casticin treatment in human cervical cancer cells, and we found that casticin generates ROS in human cervical cancer cells. Furthermore, NAC suppressed the apoptosis of HeLa cells by casticin, suggesting that the apoptotic effect was dependent on ROS generation.

Caspases play important roles in apoptosis triggered by various proapoptotic signals $(42,43)$. In general, the activation of the caspase cascade requires both initiator caspases, such as caspase-8, and -9 , and effector caspases, such as caspase-3. The effector caspases cleave several vital substrates, leading to apoptosis $(42,43)$. It has been recently well documented that the dissipation of $\Delta \Psi \mathrm{m}$, along with cytochrome c release from the mitochondria and the subsequent activation of caspase- 9 through binding to the protein Apaf-1 mediates apoptosis triggered by signals such as chemotherapeutic agents (42-44). In this study, casticin triggered $\Delta \Psi$ m dissipation, rapid release of cytochrome $\mathrm{c}$ from the mitochondria to the cytosol, activated caspase- 9 and -3 , followed by DNA fragmentation. Moreover, the pan-caspase inhibitor zVAD-FMK blocked and the caspase-9 inhibitor zLEHD-fmk suppressed casticin-induced apoptosis. Therefore, we conclude that casticin induces mitochondrial dysfunction and a cytochrome c-mediated, caspase-dependent apoptosis in human cervical cancer cells.

Kobayakawa et al reported that casticin markedly inhibited the growth of KB cells but did not inhibit the proliferation of A431 cells, which is similar to the normal cell lines 3T3 Swiss Albino and TIG-103 (22). In the present study, we showed that casticin specifically induced apoptosis in human cervical cancer cells but not in PBMCs, although the mechanism of selective induction of apoptosis has not been determined. Our findings suggest that casticin may be a specific anti-tumor agent with low toxicity.

The present study, for the first time, demonstrated that casticin induced a dose-dependent apoptosis in p53 mutated human cervical HeLa cells. Our data also highlighted the molecular mechanism of action through both ROS generation and activation of the mitochondrial apoptotic pathway, ultimately resulting in apoptosis, Our findings raise the possibility that casticin is a promising candidate for human cervical cancer therapy.

\section{Acknowledgements}

This study was supported by the Project of Scientific Research of Hunan Province the Administration Bureau of Traditional Chinese Medicine (No. 2010081), the Project of Scientific Research of Hunan Province the Department of Education (No. 10C0975) and Major Project Item of Scientific Research of Hunan Province the Department of Education (No. 09A054).

\section{References}

1. Reducing uncertainties about the effects of chemoradiotherapy for cervical cancer: a systematic review and meta-analysis of individual patient data from 18 randomized trials. J Clin Oncol 26: 5802-5812, 2008.

2. Parkin DM, Bray F, Ferlay J and Pisani P: Global cancer statistics, 2002. CA Cancer J Clin 55: 74-108, 2005.

3. Choudhury P: Preventing cervical cancer: pediatricians role. Indian Pediatr 46: 201-203, 2009.
4. Parkin DM, Bray F, Ferlay J and Pisani P: Estimating the world cancer burden: Globocan 2000. Int J Cancer 94: 153-156, 2001.

5. Baker SJ, Fearon ER, Nigro JM, et al: Chromosome 17 deletions and p53 gene mutations in colorectal carcinomas. Science 244: 217-221, 1989.

6. Ashcroft $\mathrm{M}$ and Vousden KH: Regulation of p53 stability. Oncogene 18: 7637-7643, 1999.

7. Bordon E, Henriquez Hernandez LA, Lara PC, et al: Prediction of clinical toxicity in localized cervical carcinoma by radioinduced apoptosis study in peripheral blood lymphocytes (PBLs). Radiat Oncol 4: 58, 2009.

8. Shi YJ, Zeng K, Li GF, et al: Effects of podophyllotoxin solid lipid nanoparticles on proliferation and apoptosis of cervical carcinoma cells. Nan Fang Yi Ke Da Xue Xue Bao 28: 786-788, 2008 (In Chinese).

9. The State Pharmacopoeia Commission of China, Pharmacopoeia of PRC. Chemical Industry Press, Beijin, 2000.

10. Csupor-Loffler B, Hajdu Z,Zupko I, et al: Antiproliferative effect of flavonoids and sesquiterpenoids from Achillea millefolium s.1. on cultured human tumour cell lines. Phytother Res 23: 672-676, 2009.

11. Ono M, Yanaka T, Yamamoto M, Ito Y and Nohara T: New diterpenes and norditerpenes from the fruits of Vitex rotundifolia. $\mathrm{J}$ Nat Prod 65: 537-541, 2002.

12. Diaz F, Chavez D, Lee D, et al: Cytotoxic flavone analogues of vitexicarpin, a constituent of the leaves of Vitex negundo. J Nat Prod 66: 865-867, 2003.

13. Ko WG, Kang TH, Lee SJ, et al: Polymethoxyflavonoids from Vitex rotundifolia inhibit proliferation by inducing apoptosis in human myeloid leukemia cells. Food Chem Toxicol 38: 861-865, 2000.

14. Shen JK, Du HP, Yang M, Wang YG and Jin J: Casticin induces leukemic cell death through apoptosis and mitotic catastrophe. Ann Hematol 88: 743-752, 2009.

15. Miyoshi N, Naniwa K, Yamada T, Osawa T and Nakamura Y: Dietary flavonoid apigenin is a potential inducer of intracellular oxidative stress: the role in the interruptive apoptotic signal. Arch Biochem Biophys 466: 274-282, 2007.

16. Yang XH, Zheng X, Cao JG, Xiang HL, Liu F and Lv Y: 8-Bromo-7-methoxychrysin-induced apoptosis of hepatocellular carcinoma cells involves ROS and JNK. World J Gastroenterol 16: 3385-3393, 2010.

17. Matsuo M, Sasaki N, Saga K and Kaneko T: Cytotoxicity of flavonoids toward cultured normal human cells. Biol Pharm Bull 28: $253-259,2005$

18. Chen YC, Shen SC, Chow JM, Ko CH and Tseng SW: Flavone inhibition of tumor growth via apoptosis in vitro and in vivo. Int J Oncol 25: 661-670, 2004.

19. Ling YH, Liebes L, Zou Y and Perez-Soler R: Reactive oxygen species generation and mitochondrial dysfunction in the apoptotic response to Bortezomib, a novel proteasome inhibitor, in human $\mathrm{H} 460$ non-small cell lung cancer cells. J Biol Chem 278: 33714-33723, 2003

20. Bouaziz C, Sharaf El Dein O, El Golli E, et al: Different apoptotic pathways induced by zearalenone, T-2 toxin and ochratoxin A in human hepatoma cells. Toxicology 254: 19-28, 2008.

21. Haïdara K, Zamir L, Shi QW and Batist G: The flavonoid Casticin has multiple mechanisms of tumor cytotoxicity action. Cancer Lett 242: 180-190, 2006.

22. Kobayakawa J, Sato-Nishimori F, Moriyasu M and Matsukawa Y: G2-M arrest and antimitotic activity mediated by casticin, a flavonoid isolated from Viticis Fructus (Vitex rotundifolia Linne fil.). Cancer Lett 208: 59-64, 2004.

23. Li WX, Cui CB, Cai B, Wang HY and Yao XS: Flavonoids from Vitex trifolia $\mathrm{L}$. inhibit cell cycle progression at $\mathrm{G} 2 / \mathrm{M}$ phase and induce apoptosis in mammalian cancer cells. J Asian Nat Prod Res 7: 615-626, 2005.

24. Pirollo KF, Bouker KB and Chang EH: Does p53 status influence tumor response to anticancer therapies? Anticancer Drugs 11: 419-432, 2000.

25. Kok SH, Cheng SJ, Hong CY, et al: Norcantharidin-induced apoptosis in oral cancer cells is associated with an increase of proapoptotic to antiapoptotic protein ratio. Cancer Lett 217: 43-52, 2005.

26. Reuter S, Eifes S, Dicato M, Aggarwal BB and Diederich M: Modulation of anti-apoptotic and survival pathways by curcumin as a strategy to induce apoptosis in cancer cells. Biochem Pharmacol 76: 1340-1351, 2008.

27. Cory S and Adams JM: The Bcl2 family: regulators of the cellular life-or-death switch. Nat Rev Cancer 2: 647-656, 2002. 
28. Brunelle JK and Letai A: Control of mitochondrial apoptosis by the Bcl-2 family. J Cell Sci 122: 437-441, 2009.

29. Leibowitz B and $\mathrm{Yu}$ J: Mitochondrial signaling in cell death via the Bcl-2 family. Cancer Biol Ther 9: 417-422, 2010.

30. Jurgensmeier JM, Xie Z, Deveraux Q, Ellerby L, Bredesen D and Reed JC: Bax directly induces release of cytochrome $\mathrm{c}$ from isolated mitochondria. Proc Natl Acad Sci USA 95: 4997-5002, 1998.

31. Antonsson B, Montessuit S, Lauper S, Eskes R and Martinou JC: Bax oligomerization is required for channel-forming activity in liposomes and to trigger cytochrome $\mathrm{c}$ release from mitochondria. Biochem J 345: 271-278, 2000.

32. Yang JC and Cortopassi GA: Induction of the mitochondrial permeability transition causes release of the apoptogenic factor cytochrome c. Free Radic Biol Med 24: 624-631, 1998.

33. Bradham CA, Qian T, Streetz K, Trautwein C, Brenner DA and Lemasters JJ: The mitochondrial permeability transition is required for tumor necrosis factor alpha-mediated apoptosis and cytochrome c release. Mol Cell Biol 18: 6353-6364, 1998.

34. Demarchi F and Brancolini C: Altering protein turnover in tumor cells: new opportunities for anti-cancer therapies. Drug Resist Updat 8: 359-368, 2005.

35. Munshi A, Pappas G, Honda T, et al: TRAIL (APO-2L) induces apoptosis in human prostate cancer cells that is inhibitable by Bcl-2. Oncogene 20: 3757-3765, 2001.

36. Chen D, Daniel KG, Chen MS, Kuhn DJ, Landis-Piwowar KR and Dou QP: Dietary flavonoids as proteasome inhibitors and apoptosis inducers in human leukemia cells. Biochem Pharmacol 69: 1421-1432, 2005.
37. Appierto V, Tiberio P, Villani MG, Cavadini E and Formelli F: PLAB induction in fenretinide-induced apoptosis of ovarian cancer cells occurs via a ROS-dependent mechanism involving ER stress and JNK activation. Carcinogenesis 30: 824-831, 2009.

38. Lin CW, Yang LY, Shen SC and Chen YC: IGF-I plus E2 induces proliferation via activation of ROS-dependent ERKs and JNKs in human breast carcinoma cells. J Cell Physiol 212: 666-674, 2007.

39. Wei X, Guo W, Wu S, et al: Oxidative stress in NSC-741909induced apoptosis of cancer cells. J Transl Med 8: 37, 2010.

40. Chen CC and Chan WH: Inhibition of citrinin-induced apoptotic biochemical signaling in human hepatoma $\mathrm{G} 2$ cells by resveratrol. Int J Mol Sci 10: 3338-3357, 2009.

41. Kim KK, Lange TS, Singh RK and Brard L: Lipophilic aroylhydrazone chelator HNTMB and its multiple effects on ovarian cancer cells. BMC Cancer 10: 72, 2010.

42. Thornberry NA and Lazebnik Y: Caspases: enemies within. Science 281: 1312-1316, 1998.

43. Nunez G, Benedict MA, Hu Y and Inohara N: Caspases: the proteases of the apoptotic pathway. Oncogene 17: 3237-3245, 1998.

44. Li P, Nijhawan D, Budihardjo I, et al: Cytochrome c and dATPdependent formation of Apaf-1/caspase-9 complex initiates an apoptotic protease cascade. Cell 91: 479-489, 1997. 